\title{
1 Genetic alterations and cancer formation in a European flatfish at sites of different
}

2 contaminant burdens.

$4{ }^{\dagger}$ Adélaïde Lerebours, ${ }^{\ddagger}$ Grant D. Stentiford, ${ }^{\ddagger}$ Brett P. Lyons, ${ }^{\star}$ John P. Bignell, ${ }^{\dagger}$ Stéphane A. P. Derocles 5 and ${ }^{\dagger}$ Jeanette M. Rotchell*

$7 \quad$ 'School of Biological, Biomedical and Environmental Sciences, University of Hull, Cottingham Road,

8 Hull, HU6 7RX, United Kingdom

$9{ }^{\ddagger}$ Centre for Environment, Fisheries and Aquaculture Science, Weymouth Laboratory, Barrack Road,

10 The Nothe, Weymouth, Dorset DT4 8UB, United Kingdom

12 Keywords: fish, liver cancer, retinoblastoma gene, genetic changes, contaminants

\section{Corresponding Author}

14 *Jeanette M. Rotchell, phone number: +44 (0) 1482 465333, fax number: +44 (0) 1482 465458, e-mail:

$15 \quad$ J.Rotchell@Hull.ac.uk

17 Running title: Linking $R b$ genotype, tumour phenotype and contaminant exposure in the flatfish dab. 


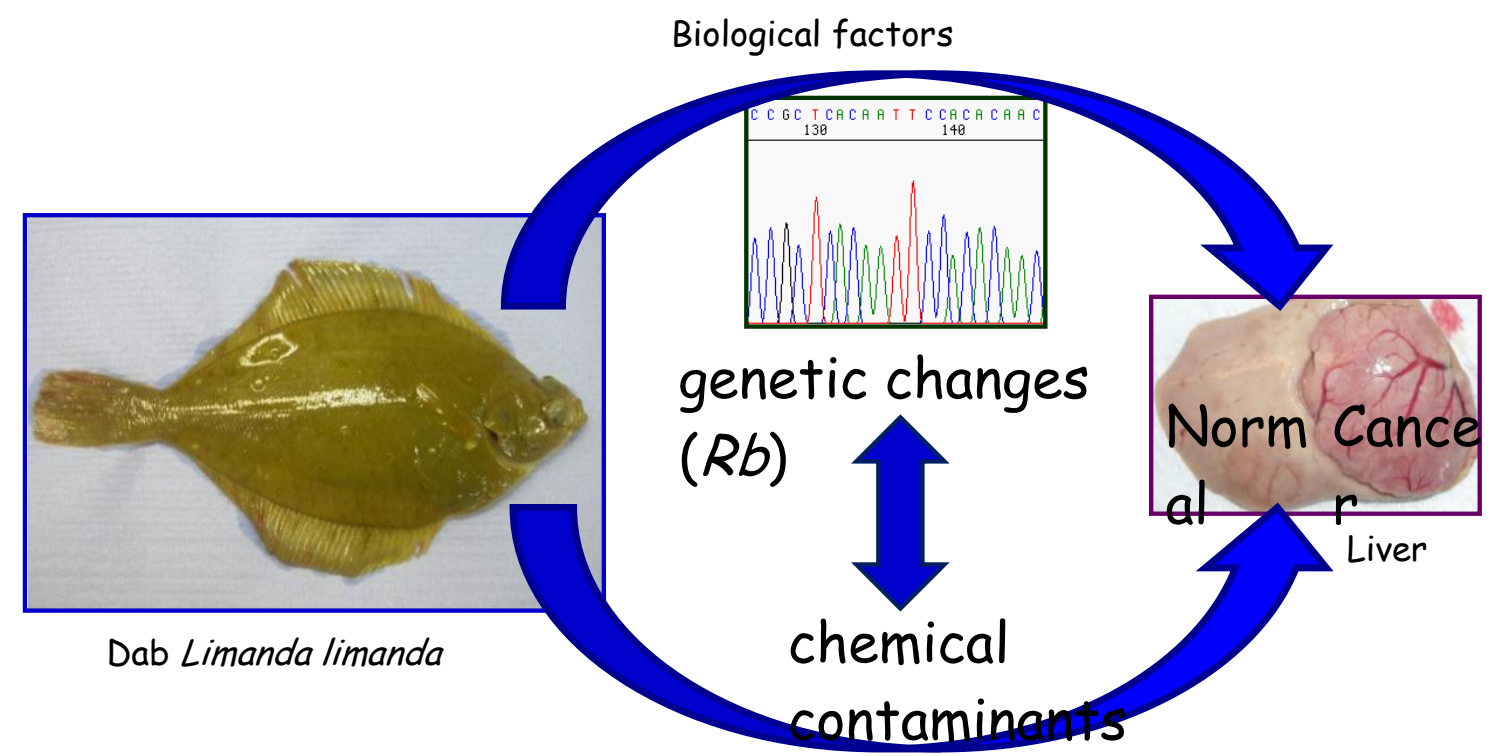

Environmental factors 


\section{Abstract}

21 Fish diseases are an indicator for marine ecosystem health since they provide a biological end-point 22 of historical exposure to stressors. Liver cancer has been used to monitor the effects of exposure to 23 anthropogenic pollution in flatfish for many years. The prevalence of liver cancer can exceed $20 \%$. 24 Despite the high prevalence and the opportunity of using flatfish to study environmentally-induced 25 cancer, the genetic and environmental factors driving tumour prevalence across sites are poorly 26 understood. This study aims to define the link between genetic deterioration, liver disease progression, 27 and anthropogenic contaminant exposures in the flatfish dab (Limanda limanda). We assessed genetic 28 changes in a conserved cancer gene, Retinoblastoma $(R b)$ in association with histological diagnosis of normal, pre-tumour and tumour pathologies in the livers of 165 fish from six sites in the North Sea and English Channel. The highest concentrations of metals (especially cadmium) and organic chemicals correlated with presence of tumour pathology and, with defined genetic profiles of the $R b$ gene, from these sites. Different $R b$ genetic profiles were found in liver tissue near each tumour phenotype, giving insight into the mechanistic molecular-level cause of the liver pathologies. Different $R b$ profiles were also found at sampling sites of differing contaminant burdens. Additionally, profiles indicated that histological 'normal' fish from Dogger sampling locations possessed $R b$ profiles associated with pretumour disease. This study highlights an association between $R b$ and specific contaminants (especially cadmium) in the molecular aetiology of dab liver tumourigenesis. 


\section{Introduction}

40 Fish diseases represent an indicator of marine ecosystem health since they provide a biological end41 point of historical exposure to stressors ${ }^{l}$. Liver pathologies of flatfish including tumours have been 42 used to monitor the effects of exposure to pollution for many years ${ }^{1-4}$. As such they are routinely used in a number of internationally co-ordinated marine monitoring programmes and have been recommended as a key tool for assessing ecosystem health by organisations including the International Council for Exploration of the Sea (ICES) and the Oslo and Paris Convention (OSPAR) Joint Assessments and Monitoring Programme (JAMP) ${ }^{5}$.

A high prevalence of dab (Limanda limanda) liver tumours, exceeding $20 \%$ at some localities in the North Sea, has been reported ${ }^{6,7}$. This prevalence is of interest both in terms of the molecular basis of tumourigenesis, and its ecological implication. Dab is a bottom-dwelling fish particularly sensitive to environmental stressors ${ }^{4}$ and can live up to 11 years making it a good indicator of the past history of contamination ${ }^{8}$. It is also widely distributed and highly abundant across the North Sea, Irish Sea and the English Channel ${ }^{9}$, facilitating population studies. The genetic structure of dab population is arguably regarded as stable over time, with a life-long residency in sampling regions proposed ${ }^{9}$. This is a fundamental criterion for sentinels of use in biomonitoring programmes. Therefore, the dab offers a unique opportunity to study environmental cancer. While there is debate among the scientific community regarding the impact of such disease on population dynamics ${ }^{10-13}$, the underlying genetic and environmental factors driving tumour prevalence across sites are still poorly documented.

Histopathology of tumours and pre-tumours in dab liver are currently diagnosed via a quality assured process involving histological tissue sections generated from wax-embedded samples ${ }^{14}$. Within the UK, such samples are collected and results are reported under the U.K. Clean Seas Environmental Monitoring Programme (CSEMP) ${ }^{6}$. Previous molecular studies using dab have 
62 revealed differences in tumour or surrounding tumour tissues as compared to normal ones, including 63 genetic alterations of cancer genes ${ }^{15-18}$, as well as differential gene expression ${ }^{6,19-21}$, protein synthesis $64{ }^{22}$, and metabolic changes ${ }^{22,23}$. Finally, Tysklind et al. (2013), observed significant interactive effects 65 between the genetic structuring of dab populations, environmental contaminants and certain liver 66 pathologies from specific sites in the North and Irish Sea. While some of these studies highlight a role 67 of chemical contaminants in the aetiology of liver pathologies, the precise mechanistic cause and effect 68 relationship, specifically at the sub-cellular / molecular level and how chemicals may interact with 69 genotype to influence tumour development, is still uncharacterised.

70 Cancer is a multi-factor disease, according to medical studies, resulting from gene-environment 71 interactions. The combination of environmental stressors such as chemicals and the susceptibility of the 72 host can result in alteration of environmentally relevant genes such as mutations in cancer genes. The 73 development of hepatocellular carcinoma (HCC) is a multistep process of transformation of normal 74 cells into malignant cells driven by accumulation of genetic and epigenetic alterations in such genes ${ }^{24-}$ $75 \quad 27$.

The $R b$ gene was the first tumour suppressor gene to be characterised ${ }^{28}$. In vertebrates, the $R b$ gene product is a nuclear phosphoprotein that regulates normal cell cycle progression. In humans, $R b$ mutations have been reported in hepatocellular carcinoma (HCC) and RB protein is inactivated in the majority of human cancers ${ }^{29} . R b$ alterations have been detected in chemically-induced retinoblastoma 80 in the medaka (Oryzias latipes), a laboratory fish model ${ }^{17}$. Dab possess both a similar 81 histopathological liver tumour profile to humans ${ }^{30}$ and homologs of human cancer genes ${ }^{15,16}$. It is 82 likely that dab and human share downstream signalling cascades underlying HCC formation; further 83 support for the suitability of this species as a relevant model of environmentally-induced liver cancer. 
The present study aims at defining the link between genetic deterioration, visible disease 85 progression and environmental contaminant burdens in a discrete population of flatfish dab ${ }^{9}$. To achieve this, the $R b$ genetic changes and histopathological diagnosis of normal, pre-tumour and tumour

87 in liver of 165 fish collected at four sites at Dogger Bank and two sites in the east English Channel, were assessed. Concentrations of metals (cadmium, Cd; mercury, $\mathrm{Hg}$; lead, $\mathrm{Pb}$; zinc, $\mathrm{Zn}$; copper, $\mathrm{Cu}$ ) and organic chemicals (polybrominated diphenyl ethers, PBDEs, and polychlorinated biphenyls, PCBs) in the liver of fish from the same sites were analysed in parallel to provide contaminant burden indication.

\section{Material and Methods}

Sample Collection

Dab (Limanda limanda) were captured at UK CSEMP sites on the Dogger Bank (North Dogger, North East Dogger, Central Dogger and West Dogger), North Sea and the English Channel (Rye Bay and Newhaven) (Table S1) during July 2010, using 30 min tows of a standard Granton trawl aboard the RV Cefas Endeavour. These sites are among those used for both ICES and OSPAR statutory monitoring and have been identified as having historically high (Dogger) or low (Rye Bay/Newhaven) prevalence

100 of liver tumours ${ }^{6,31}$. Upon landing, fish were immediately removed from the catch and placed into 101 flow-through tanks containing aerated seawater. The sex and size (total length) and presence of 102 external signs of disease were noted for each fish using methodology specified by ICES ${ }^{14}$. Otoliths were sampled from each fish and processed for age determination according to Easey \& Millner $104(2008)^{32}$. Following euthanasia, the body cavity was opened and the liver assessed for the presence of 105 macroscopic liver tumours according to the guidelines set out by Feist et al. (2004) ${ }^{14}$. For each fish $(n=$ 106 165), a standardised cross section was obtained for histological analysis and placed into $10 \%$ neutral 
107 buffered formalin and processed as described in 'Histology/histopathology'. A part of the liver from the

108 same individual fish (and beside the previous dissected fragment) was also sampled and snap frozen in

109 liquid nitrogen for molecular analysis as described in 'Total RNA, cDNA preparation and $\mathrm{Rb} c D N A$

110 isolation' below.

111

112 Chemical concentrations and biomarkers of exposure to polycyclic aromatic hydrocarbons $(P A H s)$ in

113 bile, liver or flesh from fish

114 Data pertaining to chemical and biomarker analysis was collated from the Marine Environment

115 Monitoring and Assessment National database (www.bodc.ac.uk/projects/uk/merman/), which holds

116 UK data collected to fulfill the UK's mandatory monitoring requirements under the OSPAR Joint

117 Assessments and Monitoring Programme (JAMP). In brief, the measurement of metals, PBDEs and

118 PCBs was performed on 5 pools of livers (flesh for $\mathrm{Hg}$ ) from 5 fish (representing 25 fish in total) for

119 each site. The fish were from the same trawl as the fish used in the molecular and histology analyses.

120 Chemical analyses were processed using standardised protocols as previously described for metals ${ }^{33}$,

121 PBDEs ${ }^{34}$, and PCBs ${ }^{35}$. For an indication of exposure to PAHs, bile hydroxypyrene levels and

122 ethoxyresorufin $O$-deethylase (EROD) activities were obtained from a subset of twenty fish (10 males

123 and 10 females) sampled during the same trawls at each site. The livers and gall bladders were

124 collected and analyzed for both EROD and bile measurements following standard protocols published

125 in the ICES Techniques in Marine Environmental Sciences Series (ICES TIMES). EROD activity was

126 determined in liver tissue using a fluorescent assay ${ }^{36}$. Bile samples were analyzed for fluorescent bile

127 metabolites using synchronous fluorescence spectrometry (SFS) ${ }^{37}$.

128

129 Histology/histopathology 
130 Fish were assessed for grossly visible tumours and histopathological assessment of liver samples from

131 flatfish populations collected under CSEMP. The lesions recorded include those thought to precede the

132 development of benign and malignant lesions such as foci of cellular alteration, non-neoplastic

133 toxicopathic lesions (such as nuclear and cellular polymorphism) and lesions associated with cell death,

134 inflammation and regeneration. Currently, 32 categories of liver lesion are classified under the

135 international Biological Effects Quality Assurance in Monitoring Programmes (BEQUALM) project.

136 The diagnosis of these lesion types in the dab and flounder liver follows the guidelines set out by Feist

137 et al. $(2004)^{14}$. Upon landing, dab of 20 to $30 \mathrm{~cm}$ total length from each site in each year were

138 immediately removed from the catch and placed into flow-through tanks containing aerated seawater ${ }^{14}$.

139 The sex, size (total length) and presence of grossly visible signs of disease were recorded for each fish

140 using the methodology specified by the International Council for the Exploration of the Sea (ICES) ${ }^{38}$.

141 Following grossly visible disease assessment, fish were euthanised and, upon opening of the body

142 cavity, the liver was assessed for the presence of visible tumours according to the guidelines set out by

143 Feist et al. (2004) ${ }^{14}$. Liver samples were removed and fixed for $24 \mathrm{~h}$ in $10 \%$ neutral buffered formalin

144 (NBF) before transfer to 70\% industrial methylated spirit (IMS) for subsequent histological assessment.

145 Livers were processed for formalin fixed paraffin embedded histology in a vacuum infiltration

146 processor using standard histological protocols and embedded in paraffin wax. Using a rotary

147 microtome, sections of 3-4 $\mu \mathrm{m}$ were taken and subsequently stained with haematoxylin and eosin

148 (H\&E). Slides were examined for microscopic tumours (hepatocellular adenoma and HCC) and pre-

149 tumours (vacuolated foci of cellular alteration (FCA), eosinophilic FCA, basophilic FCA), according to

150 BEQUALM and ICES criteria ${ }^{14}$ using a Nikon Eclipse E800 microscope.

152 Total RNA isolation, $c D N A$ synthesis and $\mathrm{Rb}$ cDNA isolation from individual fish 
153 For each fish an additional sample of liver (approximately $20 \mathrm{mg}$ ) was removed from near the sample 154 used in histology analysis, for parallel molecular analyses, specifically isolation of the $R b \mathrm{cDNA}$. Total 155 RNAs were extracted using the High Pure RNA Tissue kit (Roche Diagnostics Ltd, West Sussex, U.K.) 156 according to the supplier's instructions. RNA quality (integrity of $18 \mathrm{~S}$ and $28 \mathrm{~S}$ ribosomal bands) was 157 evaluated by electrophoresis on a $1 \%$ agarose-formaldehyde gel. First strand cDNAs were synthesized

158 from $1 \mu \mathrm{g}$ of total RNA using the SuperScript ${ }^{\circledR}$ VILO $^{\mathrm{TM}}$ cDNA Synthesis Kit (Invitrogen Ltd, Paisley, 159 U. K.) and according to the supplier's instructions.

160 Three overlapping parts of the coding sequence of the $R b$ cDNA: $\mathrm{RbA} 1, \mathrm{RbA} 2$ and $\mathrm{RbB}$, 161 containing the region of functional importance were amplified. Primer pairs used to amplify the region 162 between 620 and 1942 bp of the $R b$ cDNA (Accession number: AY973250) are described in Table S3 163 (contained in Supplemental Information). One $\mu \mathrm{L}$ of the reverse transcribed product was used as a 164 template for subsequent polymerase chain reaction (PCR) in a $25 \mu \mathrm{L}$ final volume using 2.5 units of the 165 Expand High Fidelity ${ }^{\text {PLUS }}$ enzyme (Roche Diagnostics Ltd, West Sussex, U.K.), primers at a final 166 concentration of $1 \mu \mathrm{M}$ and following the supplier's protocol. PCR reactions were performed using the

167 following programme: one cycle at $94^{\circ} \mathrm{C}$ for $2 \mathrm{~min}$ and 40 amplification cycles at $94^{\circ} \mathrm{C}$ for $30 \mathrm{~s}, 60^{\circ} \mathrm{C}$ 168 (RbA1) or $65^{\circ} \mathrm{C}\left(\mathrm{RbA} 2\right.$ and $\mathrm{RbB}$ ) for $30 \mathrm{~s}$, and $72^{\circ} \mathrm{C}$ for 1 min. $10 \mu \mathrm{L}$ of each PCR product were then forward and reverse sequenced commercially (Macrogen, Amsterdam, Netherlands). Both strands for 170 each overlapping fragment were assembled using the sequence-editing software CodonCode Aligner version 4.0. Sequences were aligned using ClustalW 1.81.

173 Statistical analysis

174 Statistical analyses were performed using R 3.0 (R Development Core Team 2013). The distribution 175 of different tumour stages and genetic profiles among sites, and the relation between the genetic 
176 profiles and tumour stages were first analysed by correspondence analyses, using the "dudi.coa"

177 function (ade4 package). The distribution of chemicals among sites was assessed by a principal

178 component analysis (PCA), using the "dudi.pca" function (ade4 package). The effect of the site,

179 genotype, sex and age of fish on the presence (pre-tumour and tumour) - absence (normal) of tumour

180 was also tested using generalized linear models (GLIM). All of these factors were included in the

181 model. Statistical analyses were performed using GLIM (Poisson family, link log), with the anova.glm

182 function in R. The best-fit model was selected using Akaike information criterion (AIC). Full

183 explanation of the models used to derive Figures 1-4 are given in Supplemental Information as

184 Supplemental Methods, SM1.

185

186 Results

187 Fish biometric distribution relative to locality

188 The size and weight ranges for the fish used in this study are provided in Table S2 in the Supplementary

189 Information section. In terms of the biometric data for the 165 fish sampled in this study there were

190 significant differences in the composition of the individuals at specific sampling locations as follows.

191 Fish sampled at North Dogger/Central Dogger were significantly larger/smaller than other sampling

192 sites (Table S2). Fish sampled at Dogger sites were also significantly older than fish sampled at

193 Newhaven (Table S2). However, no significant differences between fish sampled at all the sampling

194 sites were evident for Fulton Condition Index, liver weight or hepatosomatic index (HSI) (Table S2).

195 PCA statistical analysis of all the factors subsequently indicated a significant effect of site, genotype and

196 age of fish on the presence-absence of liver tumours (GLIM, site: $p=0.006$; genotype: $p=0.028$; age: $p$

$197=0.0007$; sex: $p=0.057$ ). We shall thus present the results in the order of site/locality, phenotype,

198 genotype, age and sex. 
Distribution of metals, $P C B$ s and PBDEs relative to locality

201 The concentrations of contaminants in dab liver differed significantly by site (Table S4a-c) and this 202 dataset has been used to produce a PCA plot to characterise the distribution of individual chemicals in 203 relation to site (Figure 1). For instance, the liver of fish sampled from Newhaven was characterised by 204 relatively low levels of PCB contamination (Figure 1; Table S4c), whereas that of fish sampled from 205 North Dogger was characterised by high concentrations of Cd (406 $\pm 122 \mu \mathrm{g} / \mathrm{kg}$ liver tissue)(Figure 1; 206 Table S4a). Associations between different chemical contaminants are presented in Table S5. Principal 207 component analysis showed the following highlights: the liver of fish from Rye Bay was characterised 208 by contamination with the greatest number, and highest concentrations, of PCB congeners (particularly 209 CB101, 105, 110, 138, 153 and 187)(Table S4c); fish from Newhaven less so (though PCBs still 210 formed the dominant profile)(Table S4c); those from Central, West and North East Dogger being 211 weakly associated to metals, PBDEs and PCB contamination; and those from North Dogger being most 212 associated to metals (with the highest association for Cd) (Figure 1; Table S4a-c).

214 Sampling site-specific distribution of tumour phenotypes

215 The occurrence of normal, pre-tumour (including all FCA types), and tumour liver phenotype form a 216 gradient progressing from the Newhaven to North Dogger sites (Figure 2; Figure S1). Correspondence 217 analysis revealed a gradient as follows: normal livers were mostly found in fish sampled at the 218 Newhaven site $(81 \%)$ and then at Rye Bay (67\%) and North East Dogger (66\%) to a lesser extent 219 (Figure 2; Figure S1). This latter site also contained fish displaying pre-tumours (24\%), whilst this 220 pathology also dominated in fish from the West Dogger (31\%) and Central Dogger sites (36\%)(Figure 221 2; Figure S1). In terms of prevalence, tumours were most prevalent in the livers of fish from the North 
222 Dogger site (20\%) (Figure 2; Figure S1). North Dogger was thus characterised by high Cd levels (406 $223 \pm 122 \mu \mathrm{g} / \mathrm{kg}$ liver tissue) and high liver tumour prevalence (20\%).

Different $\mathrm{Rb}$ genetic profiles are found between sites and tumour phenotypes

$226 R b$ genetic profiles were characterised in fish samples from six sites within a North Sea and English 227 Channel dab population. Four nucleotides were found to be changed in the $R b$ coding sequence at 996 bp (G to A), 1088 bp ( $\mathrm{T}$ to $\mathrm{C}$ ), $1514 \mathrm{bp}(\mathrm{G}$ to $\mathrm{T}$ ) and $1592 \mathrm{bp}$ (G to $\mathrm{T}$ ) leading to 17 different genetic profiles annotated from A to Q (Table 1). All of these changes occurred within the $R b$ sequence encoding the functionally important and conserved A and B domains.

Differing $R b$ profiles were associated with fish captured at different North Sea and English

Channel locations (Figure S2). Correspondence analysis (Figure 3) revealed three groupings: one associates fish from Newhaven, Rye Bay, Central Dogger, North East Dogger with profiles A, B, C, E, H, P and Q; a second associates fish from West Dogger with profiles D, F, G and I; and the third associates fish from North Dogger with profiles L, M, N and O (Figure 3, Table 1).

Additionally, several $R b$ profiles were identified in livers of fish displaying normal, pre-tumour and tumour phenotypes. Correspondence analysis (Figure 4) showed that five $R b$ profiles; A, D, I, Q and $\mathrm{P}$ were associated with normal liver phenotype, ten profiles; $\mathrm{B}, \mathrm{C}, \mathrm{E}, \mathrm{F}, \mathrm{H}, \mathrm{J}, \mathrm{K}, \mathrm{M}, \mathrm{N}$ and $\mathrm{O}$ are associated with liver pre-tumour stages, and profiles $\mathrm{G}$ and $\mathrm{L}$ are associated with a liver tumour phenotype (Figure 4). The differences in these $R b$ profiles hinge around only four nucleotide positions 241 of the $R b$ sequence (Table 1). On close examination of the $R b$ gene status at samples from West 242 Dogger, genotypes seen in pre-tumour fish (profiles C and D, Table 1) are also seen in normal fish 243 from that site, giving an indication that normal fish from that site on a pathogenesis trajectory to liver 244 tumour (Figures 2- 4, Table 1). 
247 The age of fish has a significant effect on the liver phenotype (normal and tumour) (GLIM1, $p=0.0007$, 248 see Supplementary Information, SM1, for full statistics). Fish from Dogger Bank are significantly older 249 than fish from Newhaven $(p<0.05$, Supplementary Information, Table S2). However, the age of fish 250 from a given site displaying normal and tumour phenotypes is similar (GLIM2, $p=0.0756$, see 251 Supplementary Information, SM1, for full statistics). The sex of fish has no effect on the phenotype 252 observed (normal and tumour) using the number of fish sampled in this study (GLIM1, $p=0.06$ see 253 Supplementary Information, SM1, for full statistics).

In summary, we link the presence of liver tumours in dab to specific contaminant classes and 255 $R b$ gene status in liver tissue next to that used in histology, providing a potential mechanism for future characterisation and prediction of disease prevalence in such populations.

\section{Discussion}

259 For the first time, this study provides a link between genetic deterioration, visible disease progression 260 and specific environmental contaminant profiles in discrete populations of marine fish. Specifically, we 261 are the first to link genetic profiles (using the $R b$ gene) to histopathological diagnosis of normal, pre262 tumour and tumour, in liver tissue of the same individual fish from different sampling sites. These 263 sampling sites have also been characterised in terms of predominant contaminant classes present in the 264 fish liver tissue, thus providing an indication of the potential causality in generation of differing $R b$ 265 genetic profiles. Such profiles also indicate that normal fish from the Dogger Bank also possess $R b$ 266 profiles associated with pre-tumour disease (Figure 2, Table 1) suggesting that such fish are possibly 267 heading towards liver tumours. 
Characteristic $\mathrm{Rb}$ profiles are associated with disease phenotype

270 In terms of $R b$ genetic profiles, four nucleotide positions were altered, corresponding to a region of 271 functional importance of the $R b$ gene, leading to 17 genetic profiles (Table 1). $R b$ profiles were not 272 randomly distributed, with specific profiles associated with both sampling site (Figure 3) and liver 273 phenotype (Figure 4). Of the $R b$ gene alterations characterised (Table 1), several were similar to those 274 found in tumours sampled from a different dab population in the Irish Sea from a previous study ${ }^{15}$. The 275 exception is one change occurring at $996 \mathrm{bp}$, corresponding to a G/G to G/A change, which has not 276 been identified previously.

Regarding the precise molecular-level biological mechanisms of cause (pollutant-induced 278 mutational activation/inactivation of key genes) and effect (pre-tumour and tumour liver phenotypes), 279 understanding the implications of these $R b$ allele zygosity patterns (contained in Table 1) are key. For instance, focussing on $R b$ profile L (Table 1), which associates with both tumour phenotype (Figure 4) and North Dogger sampling site (Figure 3), this entails heterozygosity at two of the four nucleotide positions and a homozygous alteration at another (1592 bp). For the transitional, pre-tumour phenotype, 283 the $R b$ profiles E, F, J, K, and O all display homozygous T allele at position $1592 \mathrm{bp}$. Such alterations 284 in an established tumour suppressor gene may reflect driving steps in the multi-stage progression 285 towards the tumour endpoint (as evidenced in rodent studies by Wang et al. (2012) ${ }^{39}$ ) and as such 286 require further biochemical characterisation.

Of important note is the lack of any homozygous A/A detected at position $996 \mathrm{bp}$ of the $R b$ 288 sequence (Table 1) in any of the 165 fish analysed. The latter nucleotide alteration would theoretically 289 lead to a change of amino acid involving a lysine $(\mathrm{K})$ instead of glutamic acid $(\mathrm{E})$. The glutamic acid (with polar acid properties) to lysine (with polar basic properties) alteration also occurs within the 
291 functionally conserved Domain A of the protein that is responsible for a key LxCxE motif and 292 transcription factor binding ${ }^{40}$. This theoretical change is identified as lethal phenotype $\mathrm{Rb}^{-/-}$in mice 293 embryos ${ }^{41}$. The existence of such phenotype in dab may have already had, or could have future, 294 repercussions at the population level and is of interest from the perspective of population sustainability 295 of the dab.

Related to the lethality and phenotype discussion is age, an important cofactor involved in the epidemiology of tumour development. The analyses show that the age of fish is a potentially confounding factor. In general, fish are older at Dogger Bank than at Newhaven (Table S2). In this study, no significant differences between the age of fish displaying a normal or a tumour phenotype at each site were observed. However, the limited number of fish and associated age classes make it difficult to demonstrate clear links with tumour formation in our study. Since tumourigenesis is typically a multi-stage event involving several gene activation/inactivation events, one would expect older fish to display a higher prevalence of pre-tumour and tumour phenotypes. Taking into account 304 previously published work, dab with HCA (a pre-tumour phenotype) were found in older age classes sampled from North Dogger Bank, yet no cases of HCC (actual tumour phenotype) were observed in fish of age $>5 \mathrm{yr}$ at this site ${ }^{7}$. Thus adding weight to the notion of an $\mathrm{Rb}^{-/-}$lethal phenotype.

Sex is also considered a confounding factor in the epidemiology of flatfish tumour development the statistical approach described, no influence of sex was detected for any of the variables investigated but this is undermined by low numbers of males at certain sites (Table S2). N, W and C Dogger, in 311 particular, has bigger and older fish, and the majority are females, which may in turn be due to relatively 312 low numbers of animals sampled during current study. In previous work, focusing on age primarily as a 313 confounding factor, yet importantly using very large dataset, evidence suggested that (despite some 
314 significant differences between the mean age of fish sampled from specific sites) the mean age of all

315 male (5.3 yr) and all female (4.8 yr) fish sampled during the programme was similar, and relevantly,

316 data demonstrated a very similar prevalence of specific diseases in male and female dab ${ }^{7}$.

318 Characteristic $\mathrm{Rb}$ profiles are associated with sampling site

319 Focussing on sampling sites, of particular interest are the results from North Dogger where fish livers 320 exhibit the highest prevalence (20\%) of advanced stage tumour (Figure 2; Figure S1), possess specific $321 R b$ genetic profiles (Figure 3), and display a high concentration of $\mathrm{Cd}(406 \pm 122 \mu \mathrm{g} / \mathrm{kg}$ liver 322 tissue)(Figure 1; Table S4a). While site-specific disease profiles have been reported between sampling 323 years ${ }^{6}$, these results highlight North Dogger Bank as a site of concern for prevalence of carcinogenesis 324 and involvement of $\mathrm{Cd}$. Cd is a heavy metal with no essential role in organisms, classified as a human 325 carcinogen by the International Agency for Research on Cancer, and induces cancer in several 326 organs/tissue of animals by multiple direct and indirect mechanisms ${ }^{43-45}$. The liver is a target organ of $327 \mathrm{Cd}$ toxicity in animals including fish ${ }^{42}$. Cd is a weak genotoxic chemical that inhibits DNA damage 328 repair pathways ${ }^{46}$ and apoptosis induced by toxicants ${ }^{47} . \mathrm{Cd}$ co-exposure thus enhances the 329 carcinogenic potential, or may act as a promoter, of other genotoxic chemicals, such as PAHs 330 previously identified in the molecular aetiology of liver carcinogenesis in Atlantic killifish (Fundulus 331 heteroclitus $)^{48}$, to cause cancer. This is particularly relevant for dab populations that are chronically 332 exposed to a mixture of environmental contaminants such as the case at Dogger Bank. While the PAH 333 levels are not characterised in this study, the levels of hydroxpyrene and EROD activity (124 $\pm 52 \mathrm{ng} / \mathrm{g}$ 334 and $83 \pm 58 \mathrm{pmol} / \mathrm{min} / \mathrm{mg}$ protein respectively at North Dogger, Table S6) indicate that PAHs are 335 present but at levels significantly lower than the reference sites (for instance $124 \pm 52 \mathrm{ng} / \mathrm{g}, 124 \pm 52$ 
$336 \mathrm{pmol} / \mathrm{min} / \mathrm{mg}$ protein for Newhaven)(Table S6). Further work involving controlled laboratory exposure 337 is required to confirm the exposure-effect relationship.

339 Wider implications of $\mathrm{Rb}$ involvement in fish tumour pathologies

340 In terms of wider implications and utility of this work, there are two to consider: development of an 341 early warning system and 'mutator phenotype'. Genetic modifications can occur earlier than 342 microscopic histopathological changes in the tumourigenesis process. Here we have linked for the first 343 time, $R b$ profiles in samples dissected from tissue located beside liver tissue, in the same individual 344 fish, displaying a particular liver phenotype (Figure 4). Profile data also indicates that normal fish from 345 Dogger sampling locations also possess $R b$ profiles associated with pre-tumour disease, providing an 346 indication that such fish are heading towards development of a liver tumour. Relating $R b$ profiles to 347 specific early neoplastic pre-tumour phenotype (different FCAs) may be used to predict future tumour 348 prevalence likelihoods and is subject of a current study. A limitation of the study to highlight, however, 349 is that the molecular analysis was conducted using liver tissue next to, yet not the exact same, liver 350 tissue sample used for histopathology assessment. Inherent in such an approach is the scope for false 351 negatives/positives, and that tissues of the same liver may show heterogeneity of cell type. More 352 recently, a laser capture microdissection technique to address this limitation has been optimised in dab $353{ }^{49}$. Nonetheless, this work associates $R b$ profile status with liver pathology. In addition, a second 354 mechanism of possible RB interaction, via regulators of chromatin structure including 355 methyltransferases, may be involved ${ }^{20-21,50}$. Taken together our results and those from the literature 356 highlight possible involvement of $R b$ in both genetic and epigenetic mechanisms in the aetiology of dab 357 liver tumourigenesis. 

catalyse the accumulation of further mutations, characteristic of a 'mutator phenotype' accelerating the 360 disease process ${ }^{51-52}$. The genetic instability found in our study reflects the accumulation of DNA 361 damage which is a key event driving the tumourigenesis process. In the absence of normal $R b$ gene, 362 genomic instability and chromosomal aberrations are allowed to accumulate leading to tumour 363 initiation, progression and metastasis ${ }^{53}$. The prevalence of cancer in most fish populations is extremely 364 low with background levels similar to those seen in terrestrial wild animal populations and humans ${ }^{7}$. 365 The high prevalence of HCA and other liver tumour types in dab and other marine flatfish populations 366 from coastal environments $3,7,42,54$ may be accounted for by the mutator phenotype theory. Herein we 367 also show that the flatfish model provides an opportunity to study the mechanistic molecular etiology, 368 including the relative contributing factors from the environment and the genotype, in the multi-step 369 initiation and progression of vertebrate liver cancer.

This work represents a novel approach attempting to link genetic causes (by contaminant371 induced damage in a conserved gene) to population-level biological endpoints (high prevalence of liver tumours). We assessed genetic changes in a key cancer gene, $R b$, and made a histopathological diagnosis of normal, pre-tumour and tumour in the livers of 165 fish collected at four sites at Dogger Bank and two sites in the east English Channel. Four genetic changes were found within the $R b$ sequence at functionally important sites. Characteristic $R b$ genetic profiles were found in samples beside the tissue exhibiting different tumour phenotypes, giving insight into the mechanistic molecularlevel cause of the observed liver pathologies, as well as a possible early warning tool for regulatory authorities. Characteristic $R b$ profiles were also found for sampling sites with differing contaminant burdens. This study highlights the involvement of $R b$ and specific contaminants (particularly cadmium) in the molecular aetiology of dab liver tumourigenesis. 


\section{Acknowledgements}

382 The authors wish to acknowledge the Marine Environment Monitoring and Assessment National 383 Database (MERMAN) for the provision of the supporting chemical contaminant data used in this study 384 and recognise the support of The Department of Environment, Fisheries, and Rural Affairs (Defra) for 385 funding the Clean Seas Environmental Programme, and specifically, contract \#SLA22G (to JB) for 386 completion of field sampling, histopathology and otolith assessment. Technical support in relation to 387 reading otoliths was provided by Glenn Saunders, Mark Etherton and Suzy End, while support for 388 chemical analysis was provided by Thi Bolam and Jon Barber (all Cefas).

\section{Supporting Information Available}

391 Tumour phenotype prevalence data and distribution of $\mathrm{Rb}$ genetic alleles at each sampling location are 392 supplied as additional Figures. The sampling site coordinates, biometric data, analytical chemistry data 393 plus correlation associations among chemical contaminants, and biomarkers of PAH exposure 394 (hydroxyprene levels and EROD activities) are also supplied as additional Tables. The primers used for 395 the isolation for the $R b$ cDNA are also available as an additional Table. This information is available 396 free of charge via the Internet at http://pubs.acs.org/. 
1. Stentiford, G. D.; Longshaw, M.; Lyons, B. P.; Jones, G.; Green, M.; Feist, S. W. Histopathological biomarkers in estuarine fish species for the assessment of biological effects of contaminants. Mar. Environ. Res. 2003, 55(2), 137-159.

2. Lyons ,B. P.; Stentiford, G. D.; Green, M.; Bignell, J.; Bateman, K.; Feist, S. W.; et al. DNA 403 sampled from UK estuaries. Mutat. Res. Fund. Mol. Mech. Mutagen. 2004, 552(1-2), 177-186.

3. Malins, D. C.; Krahn, M. M.; Brown, D. W.; Rhodes, L. D.; Myers, M. S.; McCain, B. B.; et al. Toxic-chemicals in marine sediment and biota from Mukilteo, Washington - relationships with hepatic neoplasms and other hepatic lesions in English Sole (Parophrys vetulus). JNCI 1985, 74(2), 487-494.

4. Vethaak, A. D.; ap Rheinallt T. Fish disease as a monitor for marine pollution: the case of the North Sea. Rev. Fish Biol. Fisheries 1992, 2(1), 1-32.

5. Lyons, B. P.; Thain, J. E.; Stentiford, G. D.; Hylland, K.; Davies, I. M.; Vethaak, A. D. Using biological effects tools to define Good Environmental Status under the European Union Marine Strategy Framework Directive. Mar. Poll. Bull. 2010, 60(10), 1647-1651.

6. Stentiford, G. D.; Bignell, J. P.; Lyons, B. P.; Feist, S. W. Site-specific disease profiles in fish and their use in environmental monitoring. Mar. Ecol. Prog. Ser. 2009, 381, 1-15.

7. Stentiford, G. D.; Bignell, J. P.; Lyons, B. P.; Thain, J. E.; Feist, S. W. Effect of age on liver pathology and other diseases in flatfish: Implications for assessment of marine ecological health status. Mar. Ecol. Prog. Ser. 2010, 411, 215-230.

8. Henderson, P. A. On the variation in dab Limanda limanda recruitment: A zoogeographic study. J. Sea Res. 1998, 40(1-2), 131-142. 
9. Tysklind, N.; Taylor, M. I.; Lyons, B. P.; Goodsir, F.; McCarthy, I. D.; Carvalho, G. R. Population genetics provides new insights into biomarker prevalence in dab (Limanda limanda L.): a key marine biomonitoring species. Evol. Appl. 2013, 6(6), 891-909.

10. De Maagd, P. G .-J.: Vethaak, A. D. (1998). Biotransformation of PAHs and their carcinogenic effects in fish. In Handbook of Environmental Chemistry; Neilson, A. H. (Ed.); Springer:

11. Grizzle, J. M.; Goodwin, A. E. Neoplasms and related lesions. In: Fish diseases and disorders Volume 2 Non-infectious disorders; Leatherland J. F., Woo, P. T. K., Eds.; CABI Publishing: Wallingford, U.K. 1998. pp. 37-104.

12. McCallum, H. 2008. Tasmanian devil facial tumour disease: lessons for conservation biology. Trends Ecol. Evol. 2008, 23(11), 631-637.

13. McAloose, D.; Newton, A. L. Wildlife cancer: a conservation perspective. Nat. Rev. Cancer 2009, 9(7), 517-526.

14. Feist, S. W.; Lang, T.; Stentiford, G. D.; Kohler, A. 2004. Biological effects of contaminants: use of liver pathology of the European flatfish dab (Limanda limanda L). ICES TIMES 2004, $38,42$.

15. du Corbier, F. A.; Stentiford, G. D.; Lyons, B. P.; Rotchell, J. M. Isolation of the retinoblastoma cDNA from the marine flatfish dab (Limanda limanda) and evidence of mutational alterations in liver tumors. Environ. Sci. Technol. 2005, 39(24), 9785-9790.

16. Rotchell, J. M.; Stagg, R. M.; Craft, J. A. Chemically-induced genetic damage in fish: isolation and characterization of the dab (Limanda limanda) ras gene. Mar. Poll. Bull. 1995, 31(4-12), 457-459. 
17. Rotchell, J. M.; Blair, J. B.; Shim, J. K.; Hawkins, W. E.; Ostrander, G. K. Cloning of the Retinoblastoma cDNA from the Japanese medaka (Oryzias latipes) and preliminary evidence of mutational alterations in chemically-induced retinoblastomas. Gene 2001, 263(1-2), 231-237.

18. Rotchell, J. M.; du Corbier, F. A; Stentiford, G. D.; Lyons, B. P.; Liddle, A. R.; Ostrander, G.

K. A novel population health approach: Using fish retinoblastoma gene profiles as a surrogate for humans. Comp. Biochem. Physiol. - C Toxicol. Pharmacol. 2009, 149(2), 134-140.

19. Small, H. J.; Williams, T. D.; Sturve, J.; Chipman, J. K.; Southam, A. D.; Bean, T. P.; et al. Gene expression analyses of hepatocellular adenoma and hepatocellular carcinoma from the marine flatfish Limanda limanda. Dis. Aquat. Org. 2010, 88(2), 127-141.

20. Mirbahai, L.; Southam, A. D.; Sommer, U.; Williams, T. D.; Bignell, J. P.; Lyons, B. P.; et al. Disruption of DNA methylation via s-adenosylhomocysteine is a key process in high incidence liver carcinogenesis in fish. J. Proteome Res. 2013, 12(6), 2895-2904.

21. Mirbahai, L.; Yin, G.; Bignell, J. P.; Li, N.; Williams, T. D.; Chipman, J. K. DNA methylation in liver tumorigenesis in fish from the environment. Epigenet. 2011, 6(11), 1319-1333.

22. Stentiford, G. D.; Johnson, P. J.; Martin, A.; Wenbin, W.; Ward, D. G.;Viant, M.; Lyons, B. P.; Feist, S.W. Liver tumours in wild flatfish: a histopathological, proteomic and metabolomic study. OMICS: J. Integrat. Biol. 2005, 9, 281-299.

23. Southam, A. D.; Easton, J. M.; Stentiford, G. D.; Ludwig, C.; Arvanitis, T. N.; Viant, M R. Metabolic changes in flatfish hepatic tumours revealed by NMR-based metabolomics and metabolic correlation networks. J. Proteome Res. 2008, 7(12), 5277-5285.

24. Baylin, S. B.; Ohm, J. E. 2006. Epigenetic gene silencing in cancer - A mechanism for early oncogenic pathway addiction? Nat. Rev. Cancer 2006, 6(2), 107-116. 
25. Feinberg, A. P.; Ohlsson, R.; Henikoff, S. The epigenetic progenitor origin of human cancer. Nat. Rev. Genet. 2006, 7(1), 21-33.

26. Jones, P. A.; Baylin, S. B. The epigenomics of cancer. Cell 2007, 128(4), 683-692.

27. Tischoff, I.; Tannapfel, A. DNA methylation in hepatocellular carcinoma. World J. Gastroenterol. 2008, 14(11), 1741-1748.

28. Friend, S. H.; Bernards, R.; Rogelj, S.; Weinberg, R. A.; Rapaport, J. M.; Albert, D. M.; et al. A human DNA segment with properties of the gene that predisposes to retinoblastoma and osteosarcoma. Nature 1986, 323(6089), 643-646.

29. Burkhart, D. L.; Sage, J. Cellular mechanisms of tumour suppression by the retinoblastoma gene. Nat. Rev. Cancer 2008, 8(9), 671-682.

30. Stern, H. M.; Zon, L. I. Cancer genetics and drug discovery in the zebrafish. Nat. Rev. Cancer 2003, 3(7), 533-539.

31. OSPAR, 2010. Quality Status Report 2010. OSPAR Commission. London 176pp.

32. Easey, M. W.; Millner, R. S. Improved methods for the preparation and staining of thin sections of fish otoliths for age determination. Sci. Ser. Tech. Rep., Cefas Lowestoft, 2008, 143, 1-12.

33. Jones, B. R.; Laslett, R. E. Methods for analysis for trace metals in marine and other samples. Aquat. Environ. Prot: Analyt. Meth., MAFF Direct. Fish. Res. Lowestoft, 1994, 11, 1-29.

34. De Boer, J.; Allchin, C.; Law, R.; Zegers, B.; Boon, J. P. Method for the analysis of polybrominated diphenylethers in sediments and biota. TrAC 2001, 20(10), 591-599.

35. Allchin, C. R.; Kelly, C. A.; Portmann, J. E. Methods of analysis for chlorinated hydrocarbons in marine and other samples. Aquat. Environ. Prot.: Analyt. Meth. MAFF Direct. Fish. Res. Lowestoft 1989, 6, 1-25.

36. Stagg, R.; McIntosh, A. Biological effects of contaminants: determination of CYP1A-dependent monooxygenase activity in dab by fluorimetric measurement of EROD activity. ICES 
Techniques in Marine Environmental Sciences 23. 1998, International Council for the Exploration of the Sea, Copenhagen, Denmark. 16 pp.

37. Ariese, F.; Beyer, J.; Jonsson, G.; Visa, C. P.; Krahn, M. M. Review of analytical methods for determining metabolites of polycyclic aromatic compounds (PACs) in fish bile. ICES Techniques in Marine Environmental Sciences 39. International Council for the Exploration of the Sea, 2005, Copenhagen, Denmark, 41 pp.

38. Bucke, D.; Vethaak, A. D.; Lang, T.; Mellergaard, S. Common diseases and parasites of fish in the North Atlantic: training guide for identification. ICES Techniques in Marine Environmental Sciences 19, 1996, ICES, Copenhagen, Denmark.

39. Wang, B.; Hikosaka, K.; Sultana, N.; Sharkar, M. T. K.; Noritake, H.; Kimura, W.; Wu, Y. X.; Kobayashi, Y.; Uezato, T.; Miura, N. Liver tumour formation by a mutant retinoblastoma protein in transgenic mice is caused by up regulation of c-Myc target genes. Biochem. Biophys. Res. Comm. 2012, 417, 601-606.

40. Lee, J. O.; Russo, A. A.; Pavletich, N. P. Structure of the retinoblastoma tumour-suppressor pocket domain bound to a peptide from HPV E7. Nature 1998, 391, 859-865.

41. Riley, D. J.; Liu, C. Y.; Lee, W. H. Mutations of N-terminal regions render the retinoblastoma protein insufficient for functions in development and tumor suppression. Mol. Cell. Biol. 1997, 17(12), 7342-7352.

42. Vethaak, A. D.; Jol, J. G.; Pieters, J. P. F. Long-term trends in the prevalence of cancer and other major diseases among flatfish in the southeastern North Sea as indicators of changing ecosystem health. Environ. Sci. Technol. 2009, 43(6), 2151-2158. 
43. Achanzar, W. E.; Webber, M. M.; Waalkes, M. P. Altered apoptotic gene expression and acquired apoptotic resistance in cadmium-transformed human prostate epithelial cells. Prostate 2002, 52(3), 236-244.

44. Waisberg, M.; Joseph, P.; Hale, B.; Beyersmann, D. Molecular and cellular mechanisms of cadmium carcinogenesis. Toxicol 2003, 192(2-3), 95-117.

45. Joseph, P. Mechanisms of cadmium carcinogenesis. Toxicol. Appl. Pharmacol. 2009, 238(3), 272-279.

46. Giaginis, C.; Gatzidou, E.; Theocharis, S. DNA repair systems as targets of cadmium toxicity. Toxicol. Appl. Pharmacol. 2006, 213(3), 282-290.

47. Mukherjee, J. J.; Gupta, S. K.; Kumar, S. Inhibition of benzopyrene diol epoxide-induced apoptosis by cadmium(II) is AP-1-independent: role of extracelluler signal related kinase. Chem. Biol. Interact. 2008, 172(1), 72-80.

48. Wills, L. P.; Jung, D.; Koehrn, K.; Zhu, S.; Willett, K. L.; Hinton, D. E.; et al. Comparative chronic liver toxicity of benzo[a]pyrene in two populations of the Atlantic killifish (Fundulus heteroclitus) with different exposure histories. Environ. Health Perspect. 2010, 118(10), 13761381.

49. Lerebours, A.; Bignell, J. P.; Stentiford, G. D.; Feist, S. W.; Lyons, B. P.; Rotchell, J. M. Advanced diagnostics applied to fish liver tumours: relating pathology to underlying molecular aetiology. Mar. Poll. Bull. 2013, 72, 94-98.

50. Robertson, K. D.; Ait-Si-Ali, S.; Yokochi, T.; Wade, P. A.; Jones, P. L.; Wolffe, A. P. DNMT1 forms a complex with RB, E2F1 and $\mathrm{HDAC} 1$ and represses transcription from E2F-responsive promoters. Nat. Genet. 2000, 25(3), 338-342. 
532 51. Hussain, S. P.; Harris, C. C. Molecular epidemiology of human cancer. Toxicol. Lett. 1998, $533 \quad 102-103,219-225$.

534 52. Loeb, K. R.; Loeb, L. A. Significance of multiple mutations in cancer. Carcinogenesis 2000, $535 \quad 21(3), 379-385$.

536 53. Di Fiore, R.; D'Anneo, A.; Tesoriere, G.; Vento, R. RB1 in cancer: Different mechanisms of 537 RB1 inactivation and alterations of pRb pathway in tumorigenesis. J. Cell. Physiol. 2013, $538 \quad 228(8), 1676-1687$.

539 54. Kranz, H.; Dethlefsen, V. Liver anomalies in dab (Limanda limanda) from the southern North 540 Sea with special consideration given to neoplastic lesions. Dis. Aquat. Org. 1990, 9, 171-185. 541 


\section{Figure and Table Legends}

544 Figure 1. Principal component analysis showing the association between concentrations of chemicals 545 in liver of fish and sampling site ( $n=30$ pools of 5 fish). Axis1 represents $60 \%$ of variance. Axis 2 546 represents $17 \%$ of variance.

547 Figure 2. Correspondence analysis showing the distribution of phenotypes (normal, pre-tumour, 548 tumour) across North Sea/English Channel sampling sites $(n=165)$. Axis1 represents 95\% of variance. 549 Axis2 represents $5 \%$ of variance.

550 Figure 3. Correspondence analysis showing the distribution of $R b$ genotypes across North Sea/English 551 Channel sampling sites $(n=165)$. Axis1 represents 38\% of variance. Axis2 represents $29 \%$ of variance. 552 Figure 4. Correspondence analysis showing the association between $R b$ genotypes and liver 553 histopathological phenotypes ( $n=165$ fish). Axis1 represents $60 \%$ of variance. Axis2 represents $40 \%$ 554 of variance.

556 Table 1. Spectrum of $R b$ genetic profiles identified in a North Sea/English Channel dab population 557 from differing localities ( $n=165$ individual fish). 


\section{$561 \quad$ Figure 1}

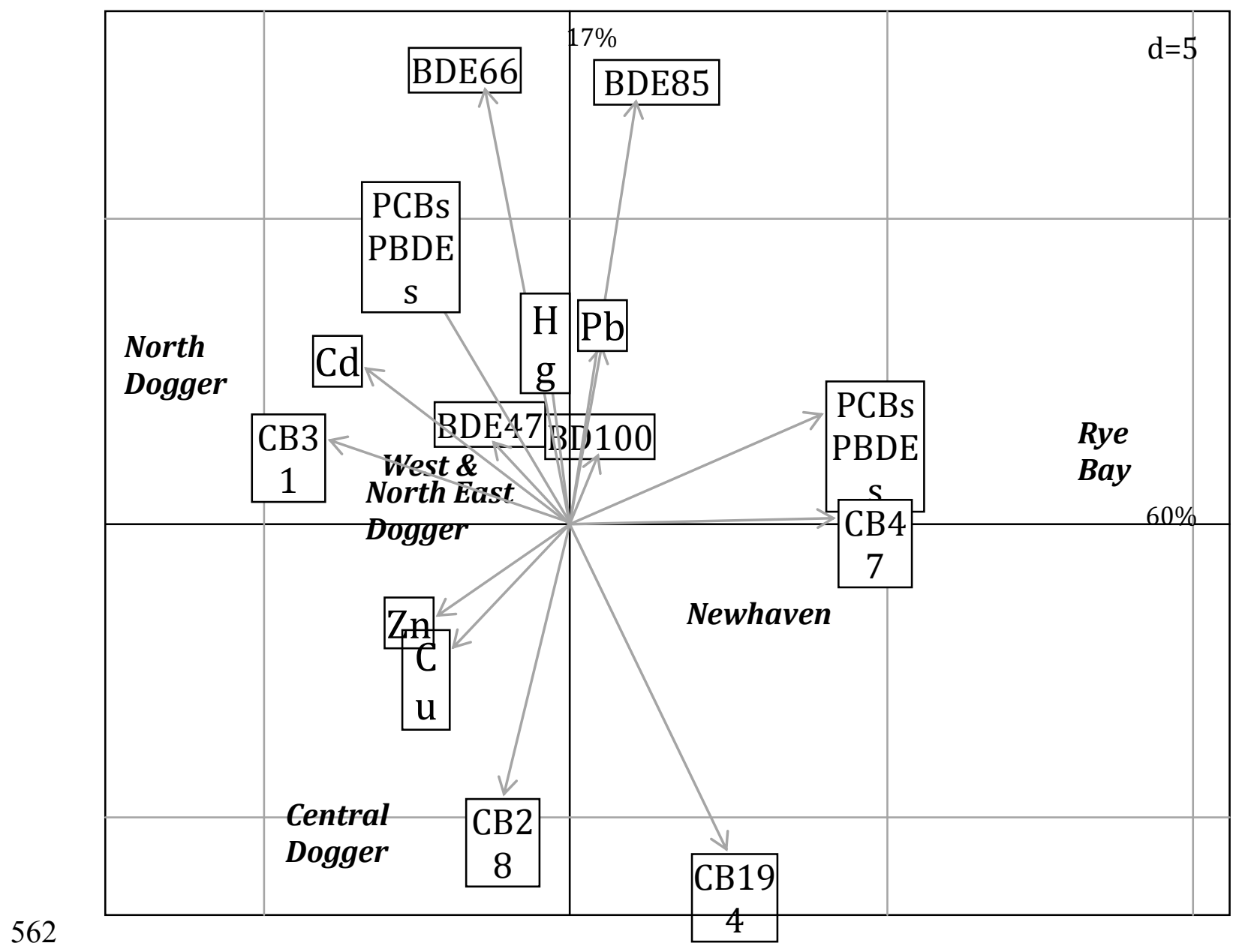

563

564

565

566

567

568 
569 Figure 2

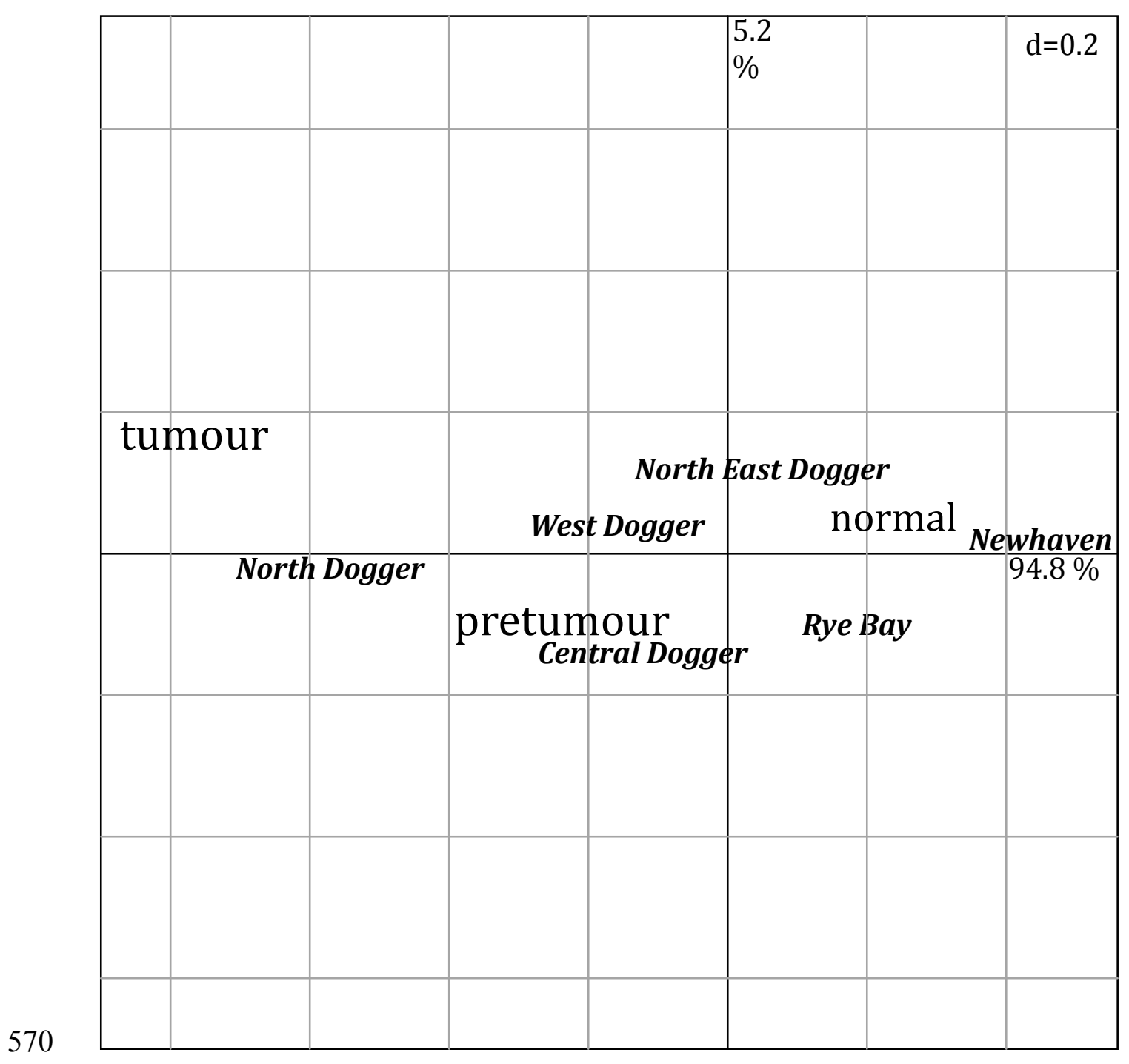

571

572

573

574

575

576 
$577 \quad$ Figure 3

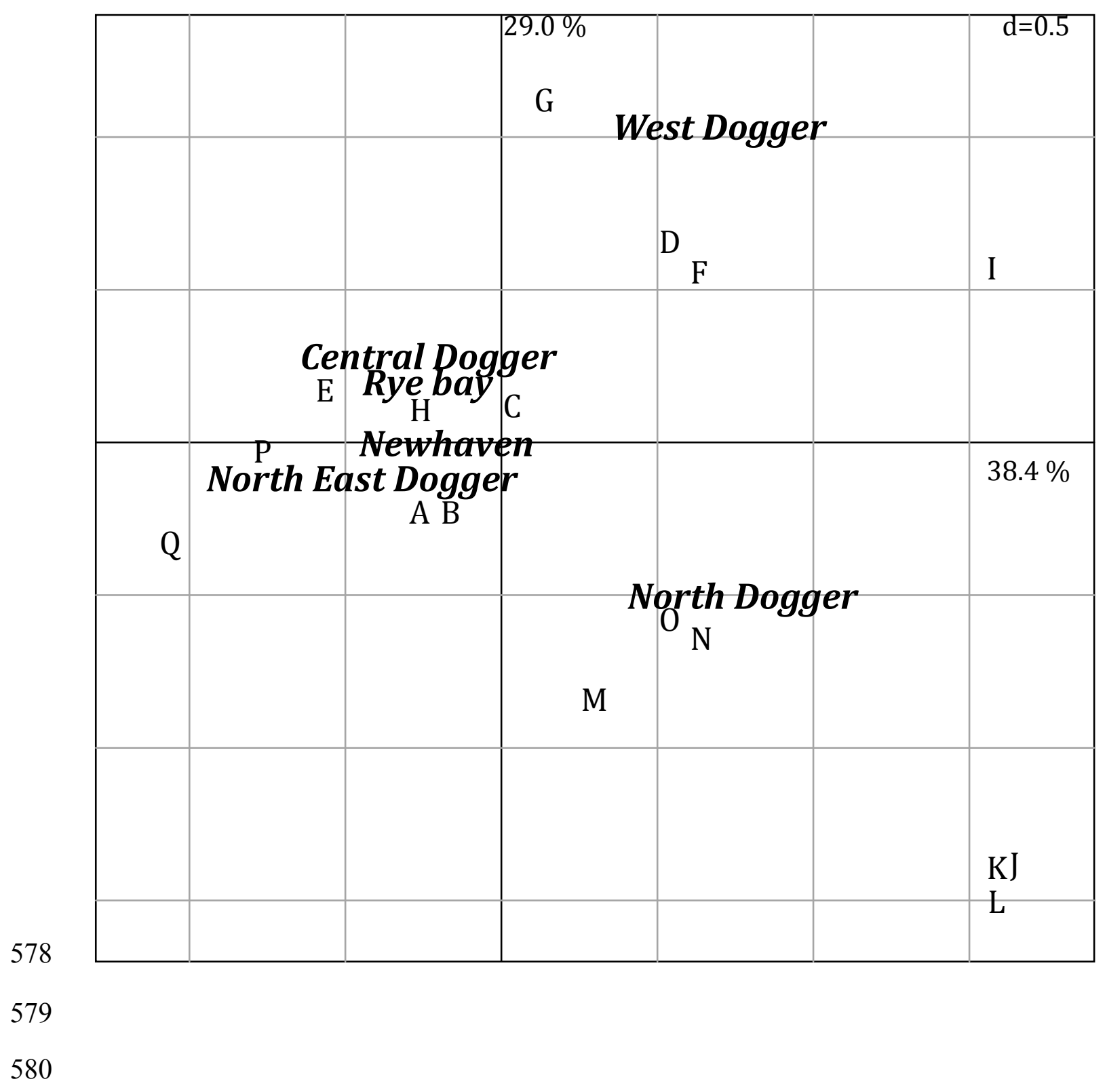

581

582

583

584 
585 Figure 4

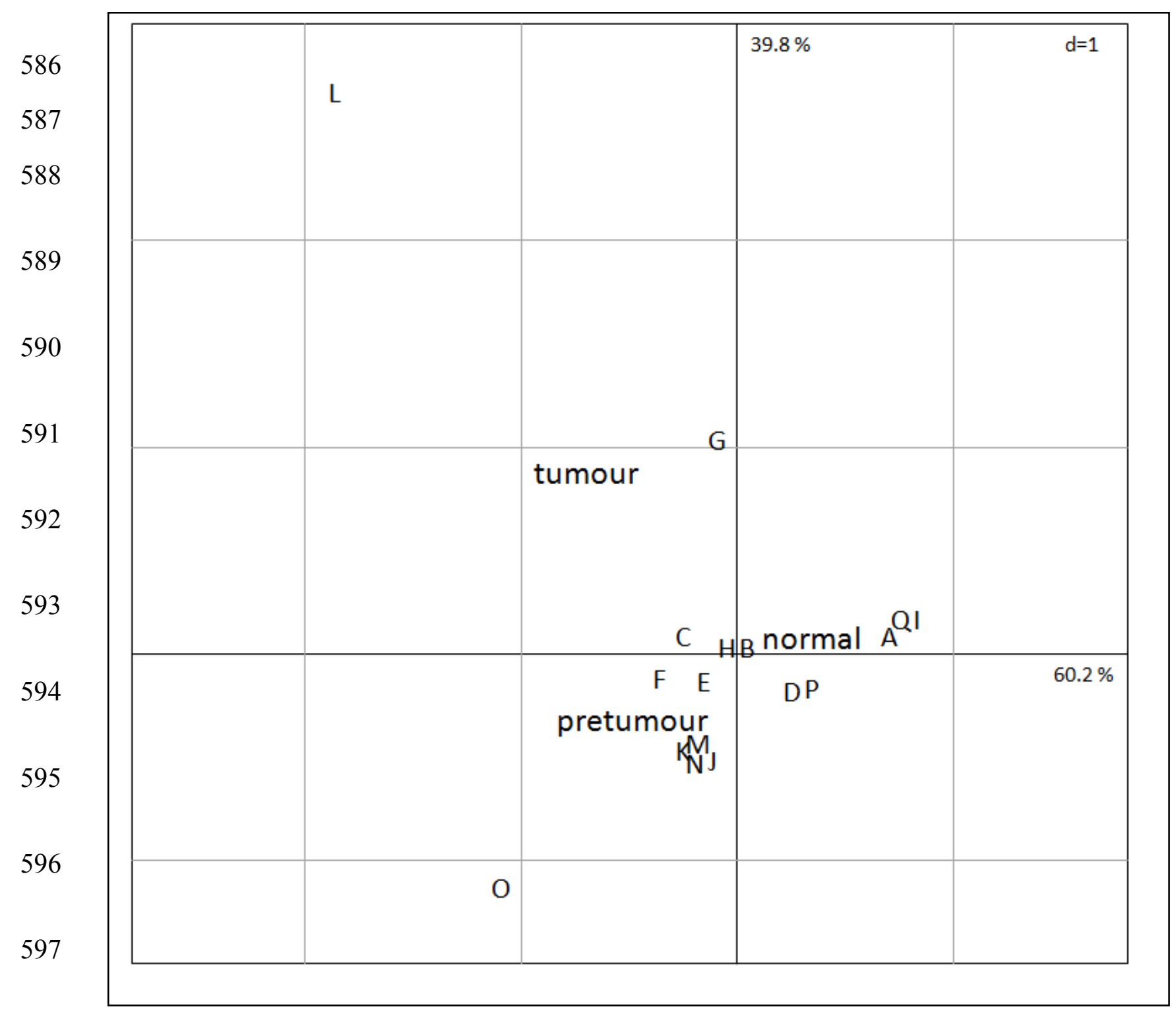

598

599

600

601

602

603 
604 Table 1

605

\begin{tabular}{ccccc}
\hline \multirow{2}{*}{ Profile name } & \multicolumn{4}{c}{$R b$ cDNA genetic changes } \\
\cline { 2 - 5 } & $996 \mathrm{bp}$ & $1088 \mathrm{bp}$ & $1514 \mathrm{bp}$ & $1592 \mathrm{bp}$ \\
\hline $\mathrm{A}$ & $\mathrm{G}$ & $\mathrm{T}$ & $\mathrm{G}$ & $\mathrm{G}$ \\
$\mathrm{B}$ & $\mathrm{G}$ & $\mathrm{T} / \mathrm{C}$ & $\mathrm{G} / \mathrm{T}$ & $\mathrm{G} / \mathrm{T}$ \\
$\mathrm{C}$ & $\mathrm{G} / \mathrm{A}$ & $\mathrm{T} / \mathrm{C}$ & $\mathrm{G} / \mathrm{T}$ & $\mathrm{G} / \mathrm{T}$ \\
$\mathrm{D}$ & $\mathrm{G} / \mathrm{A}$ & $\mathrm{T}$ & $\mathrm{G}$ & $\mathrm{G}$ \\
$\mathrm{E}$ & $\mathrm{G}$ & $\mathrm{C}$ & $\mathrm{T}$ & $\mathrm{T}$ \\
$\mathrm{F}$ & $\mathrm{G} / \mathrm{A}$ & $\mathrm{C}$ & $\mathrm{T}$ & $\mathrm{T}$ \\
$\mathrm{G}$ & $\mathrm{G} / \mathrm{A}$ & $\mathrm{T} / \mathrm{C}$ & $\mathrm{G}$ & $\mathrm{G}$ \\
$\mathrm{H}$ & $\mathrm{G}$ & $\mathrm{T} / \mathrm{C}$ & $\mathrm{G}$ & $\mathrm{G}$ \\
$\mathrm{I}$ & $\mathrm{G} / \mathrm{A}$ & $\mathrm{T}$ & $\mathrm{G} / \mathrm{T}$ & $\mathrm{G} / \mathrm{T}$ \\
$\mathrm{J}$ & $\mathrm{G} / \mathrm{A}$ & $\mathrm{C}$ & $\mathrm{G} / \mathrm{T}$ & $\mathrm{T}$ \\
$\mathrm{K}$ & $\mathrm{G}$ & $\mathrm{C}$ & $\mathrm{G} / \mathrm{T}$ & $\mathrm{T}$ \\
$\mathrm{L}$ & $\mathrm{G} / \mathrm{A}$ & $\mathrm{C}$ & $\mathrm{G} / \mathrm{T}$ & $\mathrm{G} / \mathrm{T}$ \\
$\mathrm{M}$ & $\mathrm{G}$ & $\mathrm{C}$ & $\mathrm{G}$ & $\mathrm{G}$ \\
$\mathrm{N}$ & $\mathrm{G}$ & $\mathrm{T} / \mathrm{C}$ & $\mathrm{G}$ & $\mathrm{G} / \mathrm{T}$ \\
$\mathrm{O}$ & $\mathrm{G}$ & $\mathrm{T} / \mathrm{C}$ & $\mathrm{T}$ & $\mathrm{T}$ \\
$\mathrm{P}$ & $\mathrm{G}$ & $\mathrm{C}$ & $\mathrm{G} / \mathrm{T}$ & $\mathrm{G} / \mathrm{T}$ \\
$\mathrm{Q}$ & $\mathrm{G}$ & $\mathrm{T}$ & $\mathrm{G}$ & $\mathrm{G} / \mathrm{T}$ \\
\hline
\end{tabular}

606

607

608

609

610

611

612

613

614

615

616

617 